\title{
Production of New T Cells by Thymus in Children: Effect of HIV Infection and Antiretroviral Therapy
}

\author{
RAFAEL CORREA AND M. ÁNGELES MUÑOZ-FERNÁNDEZ
}

Department of Immunology, Hospital General Universitario "Gregorio Marañón," Madrid, Spain

\begin{abstract}
ABSTR
The decrease in the number of $\mathrm{CD}^{+} \mathrm{T}$ cells during HIV
infection is the result of both peripheral destruction of cells by
the virus and inadequate replacement of these cells. Aging and
HIV infection lead to lower production of new $\mathrm{T}$ cells by the
thymus, and, therefore, a complete restoration of the immune
system is not generally achieved in infected adults after antiret-
roviral therapy. Because children have a completely functional
thymus, we addressed the effects of HIV-1 infection on the
production of new T cells in vertically infected children and
whether the decrease of viral load after therapy results in a
restoration of thymic function. To analyze the thymic function,
T-cell receptor rearrangement excision circles were measured by
quantitative PCR. Our results indicate that HIV-infected children
\end{abstract}
Depletion of $\mathrm{CD}^{+}{ }^{+} \mathrm{T}$ cells is a hallmark of HIV infection (1). Experiments using human fetal thymus tissue implanted into SCID mice demonstrated that HIV can infect human thymocytes, leading to their death $(2,3)$. Therefore, the decrease in $\mathrm{CD}^{+}{ }^{+} \mathrm{T}$ cells in HIV-infected persons would be the result of two factors: peripheral $\mathrm{CD}^{+}{ }^{+} \mathrm{T}$-cell depletion by the virus and insufficient replacement of the destroyed T cells (1).

The thymus, the organ responsible for the maturation and selection of $\mathrm{T}$ cells, undergoes involution with age. It retains, however, a reduced ability to produce new T cells in adults (4). This thymic involution with age could be responsible for the rapid progression of HIV infection in older adults because of the difficulty of generating new T cells to replace $\mathrm{CD} 4^{+} \mathrm{T}$ cells destroyed by the virus (5). In contrast, children have complete thymic function and, therefore, they have the capacity to regenerate all of the T-cell clones lost due to HIV infection, leading to a complete reconstitution of the immune system.

Received January 23, 2001; accepted February 4, 2002.

Correspondence: M. Ángeles Muñoz-Fernández, Servicio de Inmunología, HGU Gregorio Marañón, C/Dr. Esquerdo, 46, 28007 Madrid, Spain; e-mail: Mmunoz@cbm.uam.es

Supported by "Fundación para la Investigación y la Prevención del SIDA en España" (FIPSE 3008/99), "Programa Nacional de Salud" (SAF 99-0022), "Fondo de Investigaciones Sanitarias" (FIS 00/0207), Comunidad de Madrid and Bristol-Myers, S.A. (BristolMyers Squibb Group). R.C. is supported by a grant from the "Fondo de Investigaciones Sanitarias" (BEFI 99/9176). have lower T-cell receptor rearrangement excision circle levels than age-matched uninfected children, likely due to an inhibitory effect of HIV on thymic function. Additionally, in some patients, the decrease in viral load after retroviral therapy allows the generation of new $\mathrm{T}$ cells by the thymus, thus recovering the normal number of CD4 cells. (Pediatr Res 52: 207-212, 2002)

Abbreviations
TCR, T-cell receptor
TREC, TCR rearrangement excision circles
VL, viral load
ART, antiretroviral therapy
PBMC, peripheral blood mononuclear cells

Because T cells can have a very long life span, it is difficult to discriminate whether the "naive" $T$ cells present in an individual are recently produced by the thymus or whether they arose from the division of cells formed in the first stages of life. Recently, Douek et al. (4) developed an assay that allows discrimination of the $\mathrm{T}$ cells of recent formation in the thymus from those of periphery expansion. This new assay was based on the mechanism by which the repertoire of the TCR is generated. In the genetic rearrangement of the regions $\mathrm{V}, \mathrm{D}$, and $\mathrm{J}$ that produce the $\alpha \beta$ TCR (6), the deletion of the TCRD locus forms some circles of DNA-denominated signal joint TREC $(7,8)$. These circles are episomal and do not replicate during mitosis. Thus, TREC will be present only in recently produced cells by the thymus and not in those derived from the division or differentiation of older $\mathrm{T}$ cells. Moreover, the TREC only appears in the cells formed in the thymus and it is quite unlikely that extrathymic $\mathrm{T}$ differentiation can contribute to their generation (4). Therefore, the TREC constitute an excellent marker of recently emigrated $\mathrm{T}$ cells from the thymus.

Using this marker of thymic function, we have analyzed the effect of HIV infection in the production of new T cells by the thymus in children. Additionally, we have tested whether the decrease in VL after ART induces a recovery in thymic function in HIV-infected children. 


\section{PATIENTS AND METHODS}

Patients. A longitudinal study in eight HIV-infected children born to HIV-infected mothers was carried out at the Department of Immunopediatrics of the General University Hospital "Gregorio Marañón" in Madrid, Spain, between February 1995 and February 2000. Children were diagnosed as HIV-1 infected on the basis of positive results in both DNA PCR and virus culture assays, as previously described (9), and none were breast-fed. Five out of the eight HIV-infected children were studied from birth and were compared with 15 age-matched uninfected children born to HIV-infected mothers as a control group. The remaining three HIV-infected children were enrolled in the study from their first admission to the hospital (mean age at entry $18.6 \pm 8 \mathrm{mo}$ ). All infected children were treated with combination therapy consisting of combinations of two nucleoside reverse transcriptase inhibitors with or without the addition of a non-nucleoside reverse transcriptase inhibitor and/or a protease inhibitor. The treatment was prescribed by the treating physician according to Centers for Disease Control and Prevention guidelines (10) and upon obtaining written informed consent from parents or legal guardians. The antiretroviral regimens were chosen on the basis of prior treatment history and were altered, as necessary, in response to incomplete virus suppression or undesirable side effects. The study was conducted according to the Declaration of Helsinki, and approved by the ethical committee of the hospital.

$\boldsymbol{V L}$ and T-cell subsets. VL was measured in $200 \mu \mathrm{L}$ plasma using a quantitative reverse PCR assay (Amplicor Monitor, Roche Diagnostics, Basel, Switzerland), with a sensitivity of 400 RNA copies $/ \mathrm{mL}$. T-lymphocyte subsets in peripheral blood were quantified by direct immunofluorescence using $\mathrm{MAb}$ of the $\mathrm{T}$ series and flow cytometry (FACScan, BD Biosciences, San Jose, CA, U.S.A.), as previously described (9).

The measurements of VL and percentages of $\mathrm{CD}^{+}$and $\mathrm{CD} 8^{+}$lymphocytes in the HIV-infected children were performed every 2-3 mo from the birth to the end of the study.

Measurement of thymic function. TREC levels were determined in the infected children every 2-3 mo from birth to the end of the study. In the control subjects, TREC were measured every 2-3 mo from birth to the age of $15 \mathrm{mo}$.

TREC values were determined PBMC obtained from venous blood by density gradient separation using Ficoll-Hypaque (Amersham Pharmacia Biotech, Uppsala, Sweden). PBMC were then washed twice and resuspended in RPMI 1640 (Seromed, Biochrom, Berlin, Germany) medium supplemented with 10\% FCS, 2 mM L-glutamine (Flow Laboratories, Irving, U.K.), $100 \mathrm{IU} / \mathrm{mL}$ penicillin and $100 \mu \mathrm{g} / \mathrm{mL}$ streptomycin (Invitrogen, Paisley, Scotland, U.K.). PBMC (106/100 $\mu \mathrm{L})$ were lysed by incubation with $100 \mu \mathrm{g} / \mathrm{mL}$ proteinase $\mathrm{K}$ (Roche Molecular Biochemicals, Barcelona, Spain) for $2 \mathrm{~h}$ at $56^{\circ} \mathrm{C}$ and then for $15 \mathrm{~min}$ at $95^{\circ} \mathrm{C}$. TREC were quantified in $5 \mu \mathrm{L}$ of cell lysate (equivalent to 50,000 cells) by real-time quantitative PCR with a Lightcycler system (Roche Diagnostics, Mannheim, Germany). We used the hybridation probes assay that consists of one probe labeled at the 5'-end with a red fluoro- phore and, to avoid extension, modified at the 3'-end by phosphorylation: LC Red 640-TCACGAGTTGCAATGACAAGTTCAGCC-p; and a second probe labeled at the 3'-end with fluorescein: GCCCTGTCTGCTCTTCATTCACCGT-FL (TIB Molbiol, Berlin, Germany). The primers were CACATCCCTTTCAACCATGCT and CCCAGGATGGAAAACACAGTG and the PCR reactions contained FastStart DNA Master Hybridation Probes (Roche Diagnostics), $3.5 \mathrm{mM}$ $\mathrm{MgCl}_{2}, 0.5 \mu \mathrm{M}$ of each primer, and $0.2 \mu \mathrm{M}$ of each probe. Conditions were $95^{\circ} \mathrm{C}$ for $10 \mathrm{~min}$, followed by $95^{\circ} \mathrm{C}, 60^{\circ} \mathrm{C}$, and $72^{\circ} \mathrm{C}$, each for $20 \mathrm{~s}$, for 45 cycles. A standard curve was made using the pZero Blunt plasmid (Invitrogen, Carslbad, CA) that includes a fragment of $375 \mathrm{bp}$ of the TREC sequence supplied by D. Douek (4). Serial dilutions of the plasmid were amplified with the samples and a standard curve was plotted to extrapolate the number of TREC. Samples were analyzed in duplicates or triplicates, which never varied by more than $10 \%$ from each other, and the result was averaged. A $\beta$-globin control PCR was performed to verify that all the samples had the same DNA content. All samples from each child were measured in the same assay to avoid interassay variations.

Statistical analysis. Mean $\pm \mathrm{SE}$ was calculated for the seronegative healthy children. The comparison between the TREC levels in HIV-infected and HIV-uninfected groups was made using the Mann-Whitney $U$ test, because the number of samples was low in some patients and was not the same for each patient. The correlation between variables was determined using Pearson's correlation coefficient, which describes the linear relationship between two variables.

\section{RESULTS}

The effects of HIV infection on the production of new $\mathrm{T}$ cells and percentage of CD4 were analyzed during the first 15 mo of life. Five vertically HIV-infected children were studied to determine TREC values and percentage of CD4 in a total of 23 samples at different ages, and the results were compared with the values obtained from 15 age-matched healthy children. The results, shown in Figure 1, indicate that the TREC content $(p<0.01)$ and CD4 percentages $(p<0.001)$ were lower in HIV-infected children than in uninfected controls.

Next, we analyzed the effect of the ART on TREC values in the eight HIV-infected children, and how these values correlated with $\mathrm{VL}$ and percentages of $\mathrm{CD} 4^{+}$and $\mathrm{CD} 8^{+} \mathrm{T}$ cells. The start of a new treatment is represented in the figures as a vertical line. There was not a statistically significant correlation between TREC values and VL. Thus, despite an almost complete reduction of VL levels (but always remaining $>400$ copies $/ \mathrm{mL}$ ) in these children after ART, no significant variation in TREC was found. However, in some children (patients 1,2 , and 4), the dramatic decreases in VL after initiation or change of ART were followed by a marked increase in the TREC levels, and, conversely, the increases in VL after therapeutic failure were followed by a decrease in TREC values (Fig. 2).

The correlation between ART, VL, TREC, and CD4 T cells follows two different patterns (Figs. 2 and 3). Some infected children responded adequately to the treatment after the start or 


\section{Effect of HIV Infection}
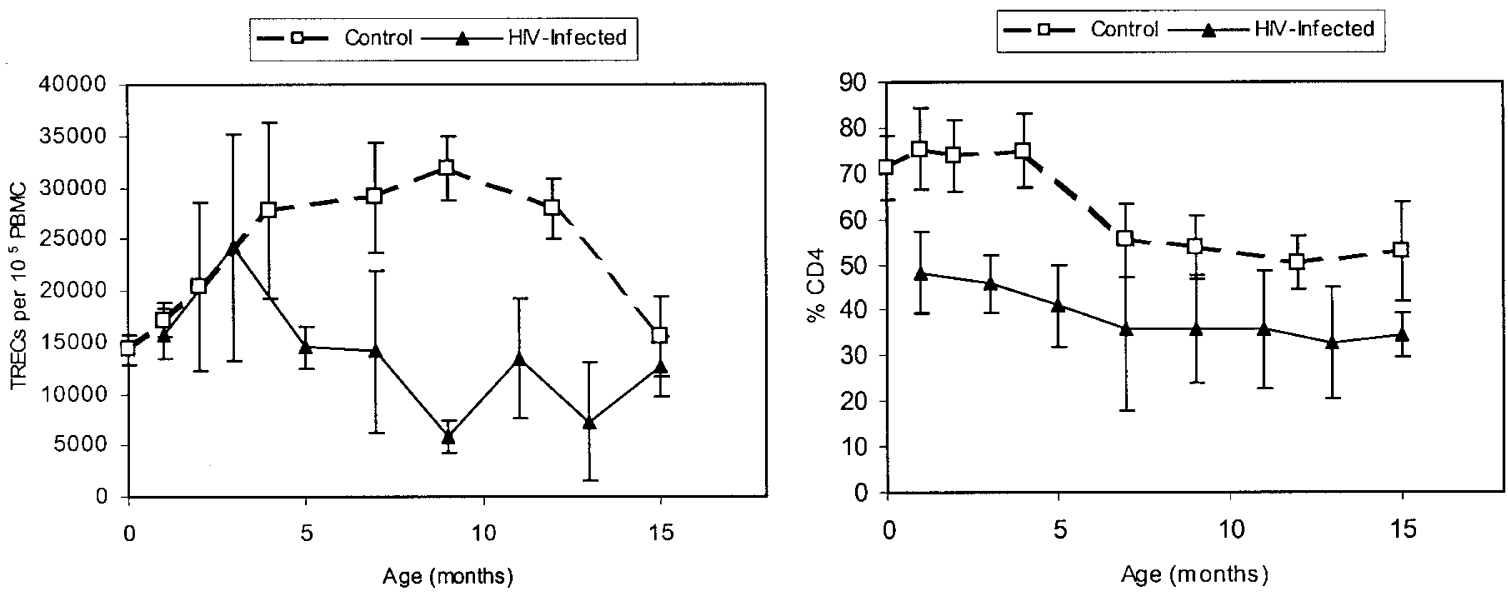

Figure 1. Evolution with age of TREC values and CD4 percentages from HIV-infected children. The control line represents the mean \pm SEM of the 15 HIV-uninfected children. The HIV-infected line represents the data obtained from birth to the age of 15 mo in five HIV-infected children. TREC levels $(p<$ $0.01)$ and percentage of CD4 $(p<0.001)$ in HIV-infected children were significantly lower than in the uninfected controls.

switching of ART, with a decrease in VL and a marked increase in percentage of CD4 (mo 9 in patient 1, mo 29 in patient 2, mo 41 in patient 8). The children whose CD4 levels increased were those who previously showed low CD4 values $(<20 \%)$, and, interestingly, the increase in CD4 was always accompanied by a concomitant increase in TREC (Fig. 3). The remaining children were those having CD4 values $>25 \%$, and, even though ART led to a decrease in VL, no significant changes in TREC and percentage of CD4 were observed. Statistical analysis supports this observation showing a significant correlation between TREC and percentage of CD4 for patients $1(p=0.020)$ and $2(p=0.005)$, whereas the remaining children did not show any significant correlation $(p$ $>0.05)$. In addition, in some instances, the decreases in percentage of CD4 coincide with a decrease in TREC levels, which in turn were associated with high VL.

Finally, TREC and percentage of CD8 T cells were compared. There was not a significant correlation between these variables $(p>0.05)$ (data not shown).

\section{DISCUSSION}

In HIV-infected children, peripheral T cells destroyed by the viral infection may be replaced by naive $\mathrm{T}$ cells newly generated from the thymus, which would allow for replacement of lost $\mathrm{T}$ cells, or by the peripheral expansion of naive and memory $\mathrm{T}$ cells (11). However, HIV can also infect and destroy human thymocytes $(2,3)$, thus jeopardizing the capacity of regeneration of new $\mathrm{T}$ cells. These effects will be more easily detected in HIV-infected children because they maintain complete thymic functionality compared with adults. Our preliminary results support this, showing that TREC levels in HIV-infected children were lower than those found in healthy children during the first 15 mo of life. This fact could contribute, in part, to the lower percentage of CD4 observed from the birth in the HIV-infected children. Previous results in adults have also found lower TREC values in HIV-infected patients $(4,12)$. These data suggest a direct effect of HIV on thymic function, which leads to a decrease in the production of new $\mathrm{T}$ cells. An alternative explanation of this fact would be an increase in peripheral T-cell expansion (i.e. $\mathrm{CD} 8^{+} \mathrm{T}$ cells) $(13$, 14) that would dilute the number of TREC in PBMC. However, in children with functional thymus, a high production of new $\mathrm{T}$ cells exists, and an inhibition of thymic function by HIV will likely have a stronger effect on the TREC levels than changes in peripheral T-cell division rates.

A recent study has also found that, in HIV-infected children, the TREC levels measured in both $\mathrm{CD}^{+}$and $\mathrm{CD} 8^{+}$subsets were lower than those found in control children (14). In that study, changes in the expansion of peripheral $\mathrm{CD} 8^{+} \mathrm{T}$ cells did not affect the TREC levels in $\mathrm{CD} 4^{+}$subset, confirming a lower production of new T cells in HIV-infected children.

Despite of the inhibitory effect of HIV on thymic function, we found no correlation between TREC and VL. However, in children with percentage of CD4 $<20 \%$, usually associated with higher VL, the decrease in VL effected by ART led to a marked increase in both CD4 and TREC. This may reflect a homeostatic mechanism that increases the production of new $\mathrm{T}$ cells only when the CD4 values are very low, and not when the CD4 values are adequate. This increase in the thymic production will be possible only with very low VL that avoids the inhibitory effect of HIV on thymus. The new highly active antiretroviral therapies may allow the decrease of VL to undetectable levels, leading to a more pronounced effect. New studies will be necessary to elucidate this fact.

We think that what determines a significant increase in TREC is not VL per se, but rather the existence of a low percentage of $\mathrm{CD}^{+} \mathrm{T}$ cells, which requires a recovery of the cell population. A marked decrease in VL, even without a 


\section{$\underline{\text { TRECs -Viral Load }}$}

Child $1 \quad \longrightarrow$ TRECs $-\Delta-$ V.L.

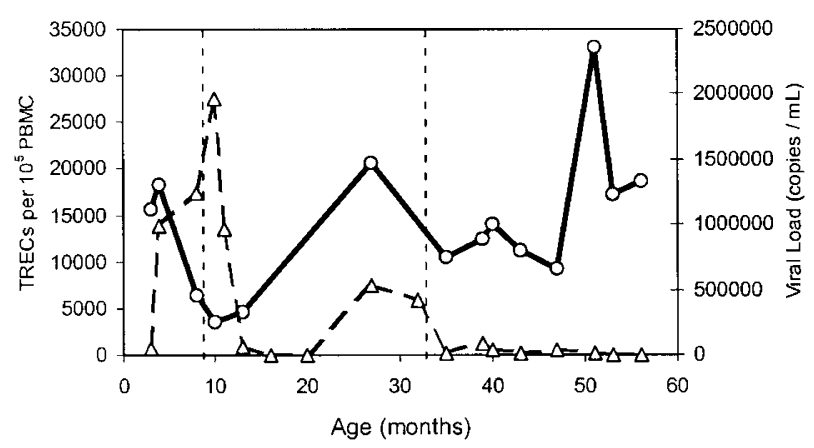

\section{Child $3 \quad \longrightarrow$ TRECs $-\Delta-$ V.L.}

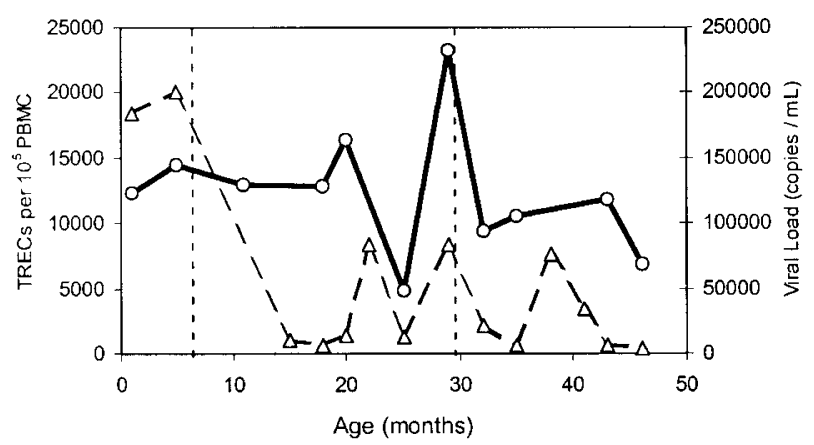

Child $5 \quad \longrightarrow$-TRECs $-\Delta-$ V.L.

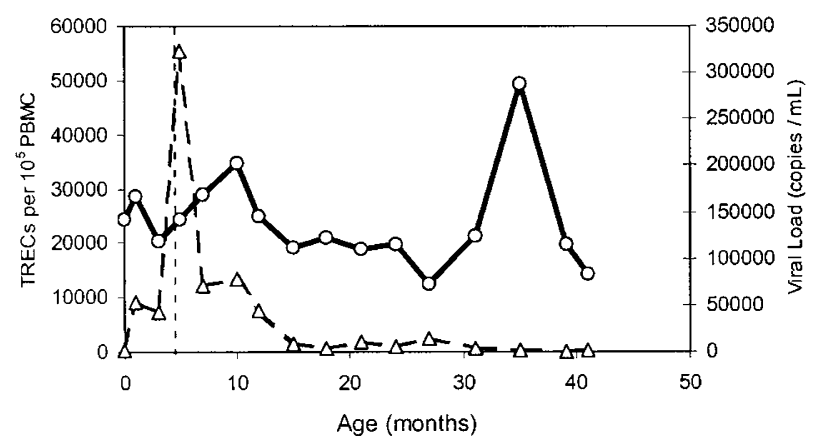

Child $7 \quad \longrightarrow$ TRECs $-\Delta-$ V.L.

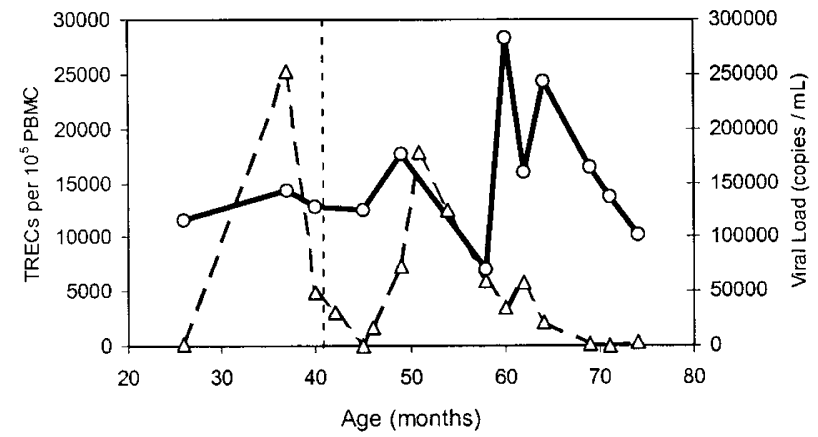

Child $2 \quad-\infty-$ TRECs $-\Delta-$ V.L.

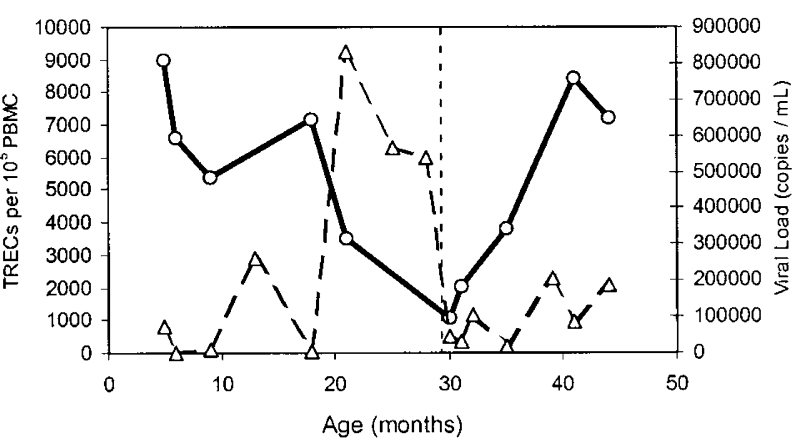

Child $4 \quad-O-$ TRECs $-\Delta-$ V.L.

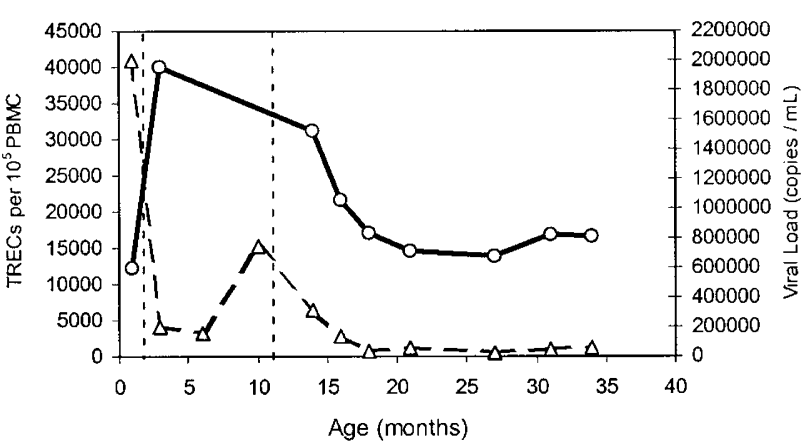

Child $6 \quad \longrightarrow$ TRECS $-\triangle-$ V.L.

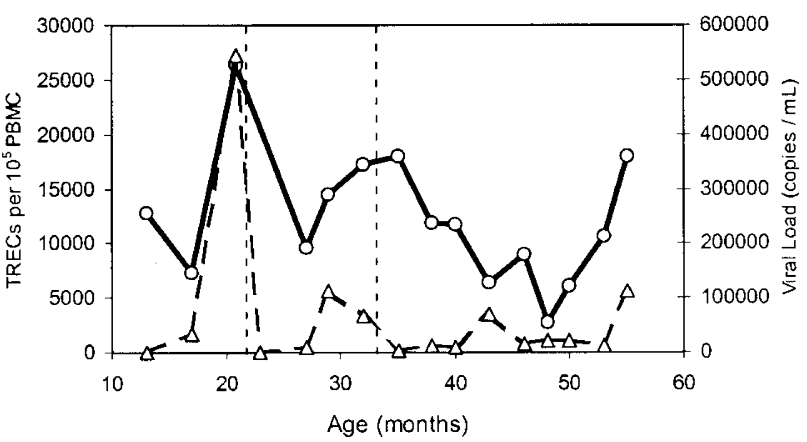

Child $8 \quad \rightarrow-$ TRECs $-\triangle-$ V.L.

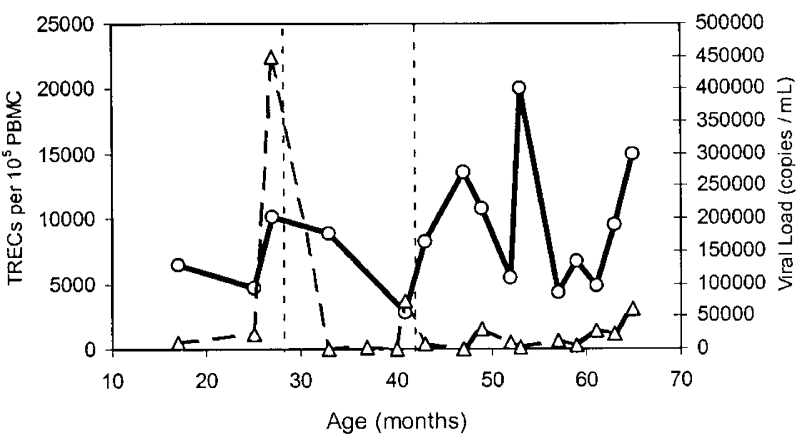

Figure 2. Evolution of TREC values and VL. TREC per $10^{5} \mathrm{PBMC}$ and VL from the eight children included in the follow-up study are represented. The vertical lines inside the graph represent the initiation of or change to a new antiretroviral treatment. 


\section{$\underline{\underline{\text { TRECS }-\% \mathrm{CD} 4}}$}
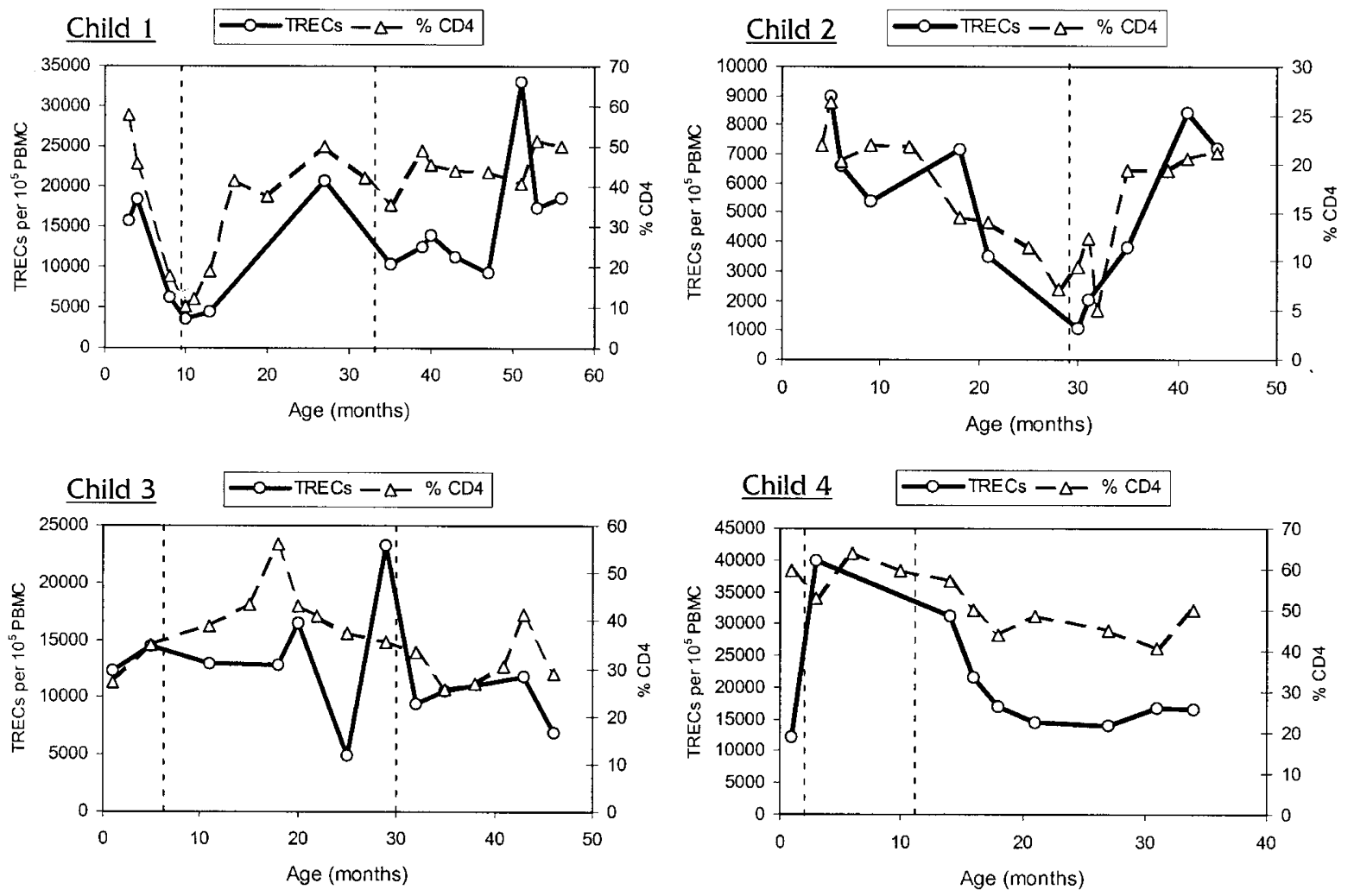

Child $5 \quad \longrightarrow$ TRECs $-\Delta-\%$ CD4
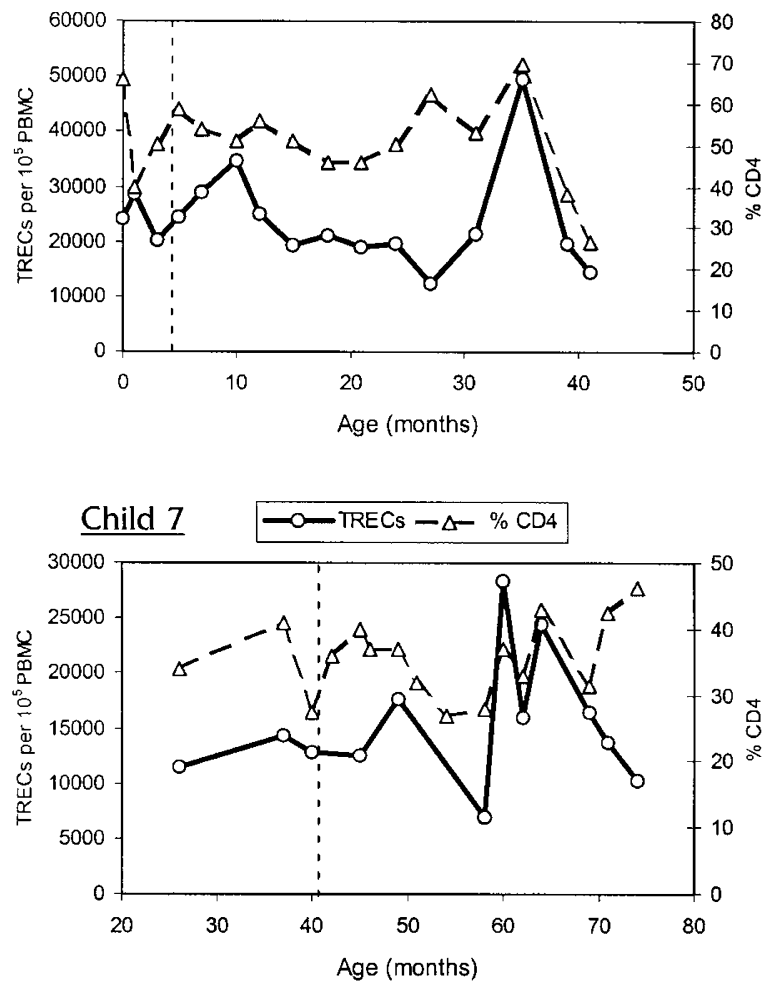

Child $6 \quad-\infty$ TRECs $-\Delta-\%$ CD4
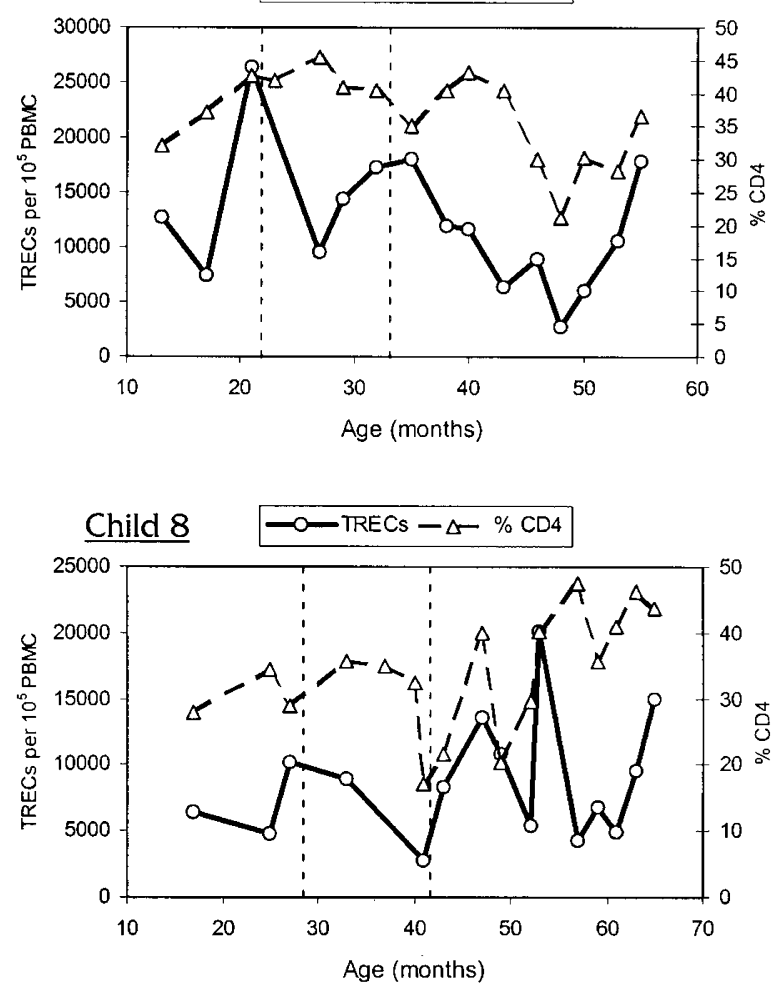

Figure 3. Evolution of the TREC values and percentage of $\mathrm{CD}^{+} \mathrm{T}$ cells. TREC per $10^{5} \mathrm{PBMC}$ and percentage of CD4 in the eight children included in the follow-up study are represented. The vertical lines represent initiation or change to a new antiretroviral treatment. There was a significant correlation $(p<0.05)$ between TREC and percentage of CD4 T cells in child 1 and child 2 . 
complete suppression, would have an effect on thymus and would restore the lost $\mathrm{T}$ cells.

This hypothesis fits well with the fact that a significant TREC recovery was only achieved in the three children with lower TREC and percentage of CD4 at the initiation or changes of ART. Moreover, the results in uninfected children, although preliminary, show a decrease in TREC from the second year of life. Taking this into consideration, the steady production of TREC in some HIV-infected children probably reflects a truly higher production than in uninfected children of the same age. To really confirm this, it will be necessary to carry out larger studies in uninfected children at different ages.

The increase in $\mathrm{CD}^{+}{ }^{+} \mathrm{T}$ cells in HIV-infected antiretroviral treated adults seems to be due to a redistribution of the $\mathrm{T}$ cells from the lymphoid organs or to a periphery expansion of $\mathrm{T}$ cells $(15,16)$. However, in our group of HIV-infected children, we observed a significant correlation between this increase in $\mathrm{CD}^{+}{ }^{+} \mathrm{T}$ cells and higher TREC levels. This indicates that the increases in $\mathrm{CD}^{+}{ }^{+} \mathrm{T}$ cells in those children are due mainly to the production of new $\mathrm{T}$ cells by the thymus (i.e. naive $\mathrm{T}$ cells). If a redistribution or increase in the division rates of peripheral $\mathrm{T}$ cells was occurring, it would produce a dilution of the new $\mathrm{T}$ cells produced by the thymus, and therefore a dilution of TREC levels.

The highest correlation with TREC levels was observed with percentage of $\mathrm{CD} 4$ and not with $\mathrm{CD} 8^{+} \mathrm{T}$ cells, probably reflecting a selective production by the thymus of the subset depleted by the infection. Moreover, previous studies have indicated that the increase in $\mathrm{CD} 8^{+} \mathrm{T}$ cells seems to be the consequence of an HIV-induced expansion and not new thymic production (17).

In conclusion, ours results, although somewhat preliminary, suggest that HIV infection produces an inhibition of the thymus function in children. Studies in larger cohorts will be necessary to confirm this effect at different ages. The decrease in VL as an effect of ART preventing the inhibitory effect of HIV on thymic function makes possible the recovery the CD4 population by a homeostatic mechanism. This indicates that the immune reconstitution in HIV-infected children could be possible and broadens the hope of new therapeutic strategies for adults.
Acknowledgments. The authors thank Daniel Douek for supplying the plasmid used for the standard curve and the method of quantification of TREC. We also thank María Chorro for her excellent technical assistance.

\section{REFERENCES}

1. Rowland-Jones S 1999 HIV infection: where have all the T cells gone? Lancet 354:5-7

2. Burke A, Anderson D, Benson W, Turnicky R, Mannan P, Liang YH, Smialek J, Virmani R 1995 Localization of human immunodeficiency virus 1 RNA in thymic tissues from asymptomatic drug addicts. Arch Pathol Lab Med 119:36-41

3. McCune JM 1997 Thymic function in HIV-1 disease. Semin Immunol 9:397-404

4. Douek DC, McFarland RD, Keiser PH, Gage EA, Massey JM, Haynes BF, Polis MA, Haase AT, Feinberg MB, Sullivan JL, Jamieson BD, Zack JA, Picker LJ, Koup RA 1998 Changes in thymic function with age and during the treatment of HIV infection. Nature 396:690-695

5. Rosenberg PS, Goedert JJ, Biggar RJ 1994 Effect of age at seroconversion on the natural AIDS incubation distribution. Multicenter Hemophilia Cohort Study and the International Registry of Seroconverters. AIDS 8:803-810

6. Bogue M, Roth DB 1996 Mechanism of V(D)J recombination. Curr Opin Immunol 8:3261-3270

7. Fujimoto S, Yamagishi H 1987 Isolation of an excision product of T-cell receptor alpha-chain gene rearrangements. Nature 327:242-243

8. Okazaki K, Davis DD, Sakano H 1987 T cell receptor beta gene sequences in the circular DNA of thymocyte nuclei: direct evidence for intramolecular DNA deletion in V-D-J joining. Cell 49:477-485

9. Munoz-Fernandez MA, Obregon E, Navarro J, Borner C, Gurbindo MD, Sampelayo TH, Fernandez-Cruz E 1996 Relationship of virologic, immunologic, and clinical parameters in infants with vertically acquired human immunodeficiency virus type 1 infection. Pediatr Res 40:597-602

10. Centers for Disease Control and Prevention 1998 Guidelines for use of antiretroviral agents in pediatric HIV infection. MMWR Morb Mortal Wkly Rep 47:RR-4

11. Mackall CL, Hakim FT, Gress RE 1997 T-cell regeneration: all repertoires are not created equal. Immunol Today 18:245-251

12. Zhang L, Lewin SR, Markowitz M, Lin HH, Skulsky E, Karanicolas R, He Y, Jin X, Tuttleton S, Vesanen M, Spiegel H, Kost R, van Lunzen J, Stellbrink HJ, Wolinsky S, Borkowsky W, Palumbo P, Kostrikis LG, Ho DD 1999 Measuring recent thymic emigrants in blood of normal and HIV-1-infected individuals before and after effective therapy. J Exp Med 190:725-732

13. Hazenberg MD, Otto SA, Stuart JW, Verschuren MC, Borleffs JC, Boucher CA, Coutinho RA, Lange JM, de Wit TF, Tsegaye A, van Dongen JJ, Hamann D, de Boer RJ, Miedema F 2000 Increased cell division but not thymic dysfunction rapidly affects the T-cell receptor excision circle content of the naive T cell population in HIV-1 infection. Nat Med 6:1036-1042

14. Douek DC, Koup RA, McFarland RD, Sullivan JL, Luzuriaga K 2000 Effect of HIV on thymic function before and after antiretroviral therapy in children. J Infect Dis 181:1479-1482

15. Autran B, Carcelain G, Li TS, Blanc C, Mathez D, Tubiana R, Katlama C, Debre P, Leibowitch J 1997 Positive effects of combined antiretroviral therapy on CD4+ T cell homeostasis and function in advanced HIV disease. J Med Chem 40:2164-2176

16. Pakker NG, Notermans DW, de Boer RJ, Roos MT, de Wolf F, Hill A, Leonard JM, Danner SA, Miedema F, Schellekens PT 1998 Biphasic kinetics of peripheral blood $\mathrm{T}$ cells after triple combination therapy in HIV-1 infection: a composite of redistribution and proliferation. Nat Med 4:208-14

17. Burgisser P, Hammann C, Kaufmann D, Battegay M, Rutschmann OT 1999 Expression of CD28 and CD38 by CD8 + T lymphocytes in HIV-1 infection correlates with markers of disease severity and changes towards normalization under treatment. The Swiss HIV Cohort Study. Clin Exp Immunol 115:458-463 